\title{
ESTAÇÃO EXPERIMENTAL DE HIDROGEOQUÍMICA (CIDADE UNIVERSITÁRIA, USP)
}

M.Szikszay ${ }^{1}$

\section{INTRODUÇÃO}

Com o aparecimento dos problemas de disposição de rejeitos contendo compostos tóxicos, estocagem de resíduos radioativos, assim como para uma melhor compreensão dos processos geoquímicos com relação à água de zona saturada, os estudos tiveram grande impulso nos últimos tempos.

Com esta finalidade, uma estação experimental foi instalada no campus da Universidade de São Paulo, sendo que esta é a primeira do gênero no Brasil (Fig. 1).

Três linhas principais de pesquisa foram previstas: estudo sobre a dinâmica, sobre variação da composição química da água da zona não saturada, assim como estudo do comportamento e da propagação de poluentes e seus tempos de trânsito e de residência.

\section{INSTRUMENTOS E MÉTODOS}

Para os estudos acima mencionados os seguintes instrumentos foram instalados e métodos utilizados:

a) Tensiômetros

Os tensiômetros são usados para determinar a direção do movimento da água, ascendente (evaporação) ou descendente (infiltração).

b) Cápsulas porosas ou extratores de água

Para o estudo do comportamento químico da água, instalaram-se a cada 0,5

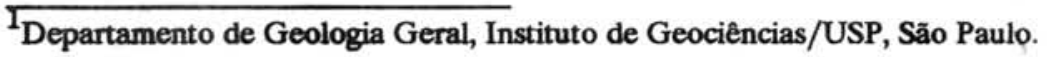


$\mathrm{m}$ de profundidade, 13 cápsulas porosas horizontais internas, 14 verticais internas e 19 verticais externas (SZIKSZAY et al., 1986).

c) ${ }_{1}^{3} \mathrm{H}$ - Trítio artificial - traçador

Para estudo do tempo de trânsito da água infiltrada foi utilizado o isótopo trítio artificial.

\section{RESULTADOS E CONCLUSÕES}

A litologia do local da estação consiste em camadas alternadas de argila, silte, areia, areia argilosa, abaixo do solo superficial de uma espessura mais ou menos 10,0 - 12,0 m.

a) Infiltração

As determinações de permeabilidade realizadas no laboratório e no local forneceram os seguintes resultados: $3,7.10^{-3} \mathrm{~cm} / \mathrm{s}$ para camadas arenosas e até $8,4.10^{-6} \mathrm{~cm} / \mathrm{s}$ para camadas argilosas, com a média de $1,45 \cdot 10^{-4} \mathrm{~cm} / \mathrm{s}$ (SZIKSZAY et al., 1987).

Com os dados de variação da precipitação atmosférica e de nível da água (3 piezômetros e 1 poço) foram realizadas regressões lineares e os resultados mostram que a infiltração ocorre de 50-170 dias.

Estudos com trítio $\left({ }_{1}^{3} \mathrm{H}\right)$ mostram que, por estes métodos, tem-se infiltrado $600 \mathrm{~mm}$ de água em 5 meses.

\section{b) Dinâmica}

Para interpretar os resultados dos estudos com as medidas tensiométricas, os dados foram tratados pelo programa "PLOT/SURF".

Os resultados mostram que, dependendo da estação do ano, a linha de evaporação varia de $0,5-1,5 \mathrm{~m}$ de profundidade.

A carga hidráulica é menor no fim de inverno e na primavera, quando ocorre, principalmente, a evaporação e é maior na época das chuvas, correspondendo à recarga do aqüffero.

Os estudos com os tensiômetros têm as seguintes aplicações:

- na hidrogeologia, para conhecer a época e a duração de recarga do aqüífero;

- na agricultura, para saber quando irrigar e a quantidade de água a ser usada (depende da profundidade da linha de evaporação);

- na prevenção de poluição por defensores agrícolas, para não aplicar fertilizantes, pesticidas, etc., durante a época de recarga do aqüífero. 
c) Composição química da água na zona não saturada

A composição química da água na zona não saturada tem importância somente local, sendo que as maiores concentrações de compostos solúveis na parte próxima à superfície são regidas pela posição da linha de evaporação $(0,5-1,5 \mathrm{~m})$. Na parte superior, os fatores que influem na variação da composição química são predominantemente climáticos e influenciados pela presença de vegetação, enquanto que na profundidade são litológicos. Tratando-se de clima subtropical mais ou menos uniforme, não se constataram grandes variações na composição química com as estações (SZIKSZAY et al., 1988).

d) Correlação entre composição química da água e a mineralogia

A mineralogia do perfil é principalmente composta de quartzo, caulinita, esmectita, goethita e em quantidade menores, muscovita e raramente microclínio. Os resultados mostraram que existe um processo lento de caulinitização sobre a muscovita $\mathrm{e}$ microclínio, liberando o $\mathrm{K}^{+}$o que é refletido em concentrações mais elevadas deste elemento nas águas percolantes (SZIKSZAY \& TOLEDO-GROKE, 1989).

e) Classificação das águas na zona não saturada da estação experimental

As águas se classificam como cloretadas sódicas e cloretadas mistas na parte superior da zona não saturada, passando para bicarbonatadas mistas, bicarbonatada mistassódicas até cloretadas sódicas em profundidade, refletindo a influência do clima na parte superior e da litologia na parte inferior do perfil (SZIKSZAY et al., 1989).

O conhecimento da composição química da água e dos processos químicos na zona não saturada tem várias aplicações:

- variação da composição química, mostrando existência ou ausência da influência de água percolante através da zona não saturada para a composição química das águas do aqüífero;

- correlação da composição química da água com a mineralogia. estudando os processos de interação na formação de novos minerais;

- na poluição, para verificar a existência ou ausência de adsorção ou precipitação na zona não saturada, evitando assim a transferência de poluentes até o aqüífero;

- no estudo preliminar de estocagem de resíduos radioativos, onde fora das características da matriz porosa da zona não saturada, precisa estudar diversos parâmetros relativos à água (velocidade do movimento, idade, origem, etc.).

\section{REFERÊNCIAS BIBLIOGRÁFICAS}


SZIKSZAY, M.; CONSONI, A.J.; GUIGUER, N.; HASSUDA, S.; KIMMELMANN, A.A.; PARISOT, E.; SGAMBATO, E.; YOSHINAGA, S. (1986) Instalação de uma Estação Experimental para estudo da dinâmica e da evolução da composição química da água na zona não saturada. Águas Subterrâneas, (10):5-20.

SZIKSZAY, M.; CONSONI, A.J.; YOKOTA, H.K; ARAUJO, J.R.; DUARTE, U.; KANEHISHA, M.S. (1987) Estudo preliminar da hidrodinâmica na zona não saturada da Estação Experimental (Cidade Universitária, São Paulo). Águas Subterrâneas, (11):3362 .

SZIKSZAY, M.; HYPOLITO, R.; KIMMELMANN, A.A.; FIGUEIREDO, R.M.; ORLANDO, R.; SAMESHIMA, R.H. (1988) Estudo hidrogeológico e hidrogeoquímico na zona não saturada. In: CONGRESSO BRASILEIRO DE ÁGUAS SUBTERRÂNEAS, 5., São Paulo, 1988. Anais. São Paulo, p.133-143.

SZIKSZAY, M. \& TOLEDO-GROKE, M.C. (1989) Correlation of the chemical composition of water from the unsaturated zone with the mineralogy of a profile on the São Paulo Basin, Brazil. In: INTERNATIONAL SYMPOSIUM ON WATER/ROCK INTERACTION, 6., Malvern, U.K., 1989. Proceedings. Rotterdam, A.A. Balkema. p.669-672.

SZIKSZAY, M.; KIMMELMANN, A.A.S.; HYPOLITO, R. (1989) Estudo hidrogeoquímico da zona não saturada em terrenos subtropicais úmidos. In: CONGRESSO BRASILEIRO DE GEOQUÍMICA, 2., Rio de Janeiro, 1989. Anais, Rio de Janeiro, Sociedade Brasileira de Geoquímica, CPRM/DNPM. p.329-337. 


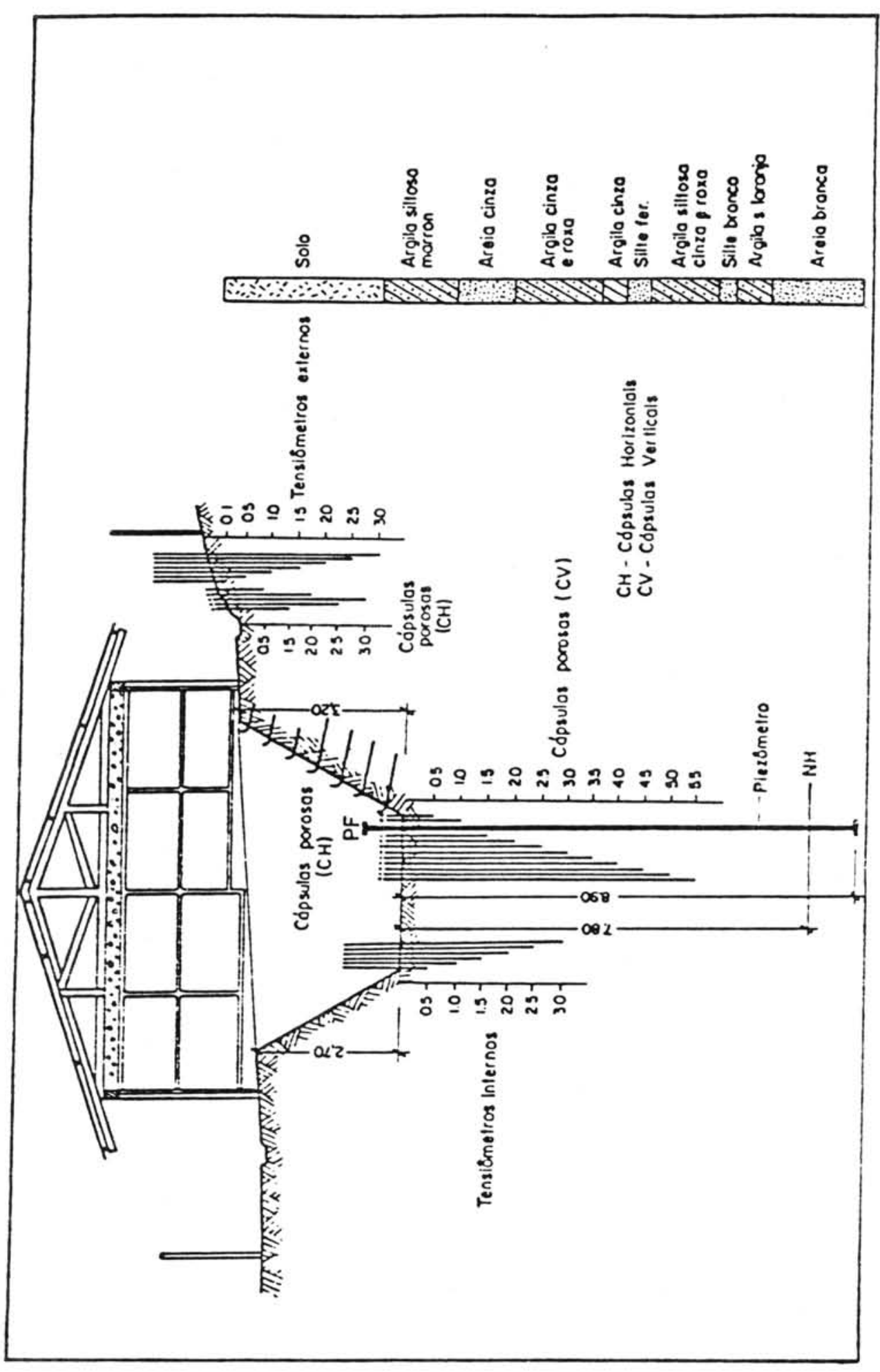

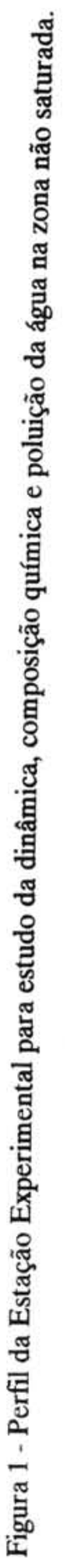

